\title{
The Canonical Nuclear Factor- $\kappa$ B Pathway Regulates Cell Survival in a Developmental Model of Spinal Cord Motoneurons
}

\author{
Stefka Mincheva, ${ }^{1}$ Ana Garcera, ${ }^{1 \star}$ Myriam Gou-Fabregas, ${ }^{1 \star}$ Mario Encinas, ${ }^{2}$ Xavier Dolcet, ${ }^{2}$ and Rosa M. Soler ${ }^{1}$ \\ ${ }^{1}$ Unitat de Senyalització Neuronal, Departament de Ciències Mèdiques Bàsiques, Facultat de Medicina, Universitat de Lleida-Institut de Recerca Biomèdica \\ de Lleida (IRBLLEIDA), 25008 Lleida, Spain, and 2Research Laboratory and Department of Pathology and Molecular Genetics, Laboratori de Recerca \\ and Departament de Genetica Molecular, Hospital Universitari Arnau de Vilanova-IRB Lleida, 25198 Lleida, Spain
}

In vivo and in vitro motoneuron survival depends on the support of neurotrophic factors. These factors activate signaling pathways related to cell survival or inactivate proteins involved in neuronal death. In the present work, we analyzed the involvement of the nuclear factor- $\kappa \mathrm{B}(\mathrm{NF}-\kappa \mathrm{B})$ pathway in mediating mouse spinal cord motoneuron survival promoted by neurotrophic factors. This pathway comprises ubiquitously expressed transcription factors that could be activated by two different routes: the canonical pathway, associated with IKK $\alpha / \mathrm{IKK} \beta$ kinase phosphorylation and nuclear translocation RelA (p65)/p50 transcription factors; and the noncanonical pathway, related to IKK $\alpha$ kinase homodimer phosphorylation and RelB/p52 transcription factor activation. In our system, we show that neurotrophic factors treatment induced IKK $\alpha$ and IKK $\beta$ phosphorylation and RelA nuclear translocation, suggesting NF- $\kappa \mathrm{B}$ pathway activation. Protein levels of different members of the canonical or noncanonical pathways were reduced in a primary culture of isolated embryonic motoneurons using an interference RNA approach. Even in the presence of neurotrophic factors, selective reduction of IKK $\alpha$, IKK $\beta$, or RelA proteins induced cell death. In contrast, RelB protein reduction did not have a negative effect on motoneuron survival. Together these results demonstrated that the canonical NF- $\kappa$ B pathway mediates motoneuron survival induced by neurotrophic factors, and the noncanonical pathway is not related to this survival effect. Canonical NF- $\kappa$ B blockade induced an increase of Bim protein level and apoptotic cell death. Bcl- $\mathrm{x}_{\mathrm{L}}$ overexpression or Bax reduction counteracted this apoptotic effect. Finally, RelA knockdown causes changes of CREB and Smn protein levels.

\section{Introduction}

Neuronal survival and apoptosis play a critical role in the development of the nervous system by eliminating superfluous neurons and ensuring proper connections. One family of molecules that plays a role in the maintenance of neuronal survival, blocking apoptosis, is the transcription factor nuclear factor- $\kappa \mathrm{B}$ (NF$\kappa \mathrm{B})$ (Bhakar et al., 2002). Inhibition of NF- $\kappa \mathrm{B}$ activity causes neuronal death in a variety of neurodegenerative models (Koulich et al., 2001); reduced NF- $\kappa \mathrm{B}$ activity has been involved in

Received Jan. 13, 2011; revised Feb. 23, 2011; accepted March 3, 2011.

Author contributions: S.M. and R.M.S. designed research; S.M., A.G., and M.G.-F. performed research; M.E. and X.D. contributed unpublished reagents/analytic tools; S.M., A.G., M.G.-F., and R.M.S. analyzed data; S.M. and R.M.S. wrote the paper.

${ }^{*}$ A.G. and M.G.-F. contributed equally to this work.

This work was supported by grants to R.M.S. from Instituto de Salud Carlos III-Fondo de Investigaciones Sanitarias (P1080267), the Ministerio de Ciencia e Innovación [Consolider-Ingenio 2010 (CSD2007-00020)], and the Generalitat de Catalunya (Suport Grups de Recerca Emergents) (2009SGR740); and to M.E. from the Ministerio de Ciencia e Innovación (BFU2007-67619). S.M. holds a fellowship from Comissionat per a Universitats i Recerca del Departament d'Innovació, Universitats i Empresa de la Generalitat de Catalunya i del Fons Social Europeu; A.G. holds a postdoctoral contract from GENOMA España (GENAME project); M.G.-F. holds a fellowship from Universitat de Lleida. We especially thank Prof. Joan X. Comella for providing the BCl- $x_{L}$ plasmid construct, Dr. Montserrat Rue for statistics support, and Berta Daussa for technical assistance. We also thank Dr. Elaine Lilly (Writer's First Aid) for English language revision of the manuscript.

Correspondence should be addressed to Rosa M. Soler, Unitat de Senyalització Neuronal, Departament de Ciències Mèdiques Bàsiques, Facultat de Medicina, Universitat de Lleida-Institut de Recerca Biomèdica de Lleida, Montserrat Roig 2, 25008-Lleida, Spain. E-mail: rosa.soler@cmb.udl.cat.

DOI:10.1523/JNEUROSCI.0206-11.2011

Copyright $\odot 2011$ the authors $\quad 0270-6474 / 11 / 316493-11 \$ 15.00 / 0$ disorders such as Alzheimer disease, Parkinson disease, and amyotrophic lateral sclerosis (Mattson et al., 2000).

$\mathrm{NF}-\kappa \mathrm{B}$ is a ubiquitously expressed transcription factor system that consists of homodimers and heterodimers of five structurally related proteins: RelA/p65, RelB, c-Rel, p50, and p52, of which the p50/RelA heterodimer is the most abundant and widely expressed. RelA, RelB, and c-Rel contain domains that activate transcription without the help of other NF- $\kappa$ B subunits (Kaltschmidt et al., 2005). NF- $\kappa \mathrm{B}$ is held in an inactive form in the cytosol by interaction with the inhibitor protein I $\kappa$ B (Hayden and Ghosh, 2004). There are distinct NF- $\kappa \mathrm{B}$ activation pathways. The most frequently observed is the canonical pathway that consists of the transcription factor dimer RelA/p65, and is typified by the phosphorylation of $\mathrm{I} \kappa \mathrm{B} \alpha$ on serine $32 / 36$ residues and proteasome degradation. Liberated RelA/p65 translocates to the nucleus, resulting in gene induction or gene repression. Canonical pathway activity depends on the catalytic subunits IKK $\alpha$ and IKK $\beta$ of the I $\kappa$ B kinase complex (IKK) (Perkins, 2007).

In the nervous system, NF- $\kappa \mathrm{B}$ is activated by a variety of neurotrophic factors (NTFs). NF- $\kappa \mathrm{B}$ promotes neuroprotection or neurodegeneration, but also regulates neuronal functions such as neurite growth (Kaltschmidt et al., 2005; Gallagher et al., 2007; Gutierrez et al., 2008). In the present work, we investigated whether NF- $\kappa \mathrm{B}$ signaling mediates the survival effect induced by NTFs on the spinal cord motoneurons (MNs). The large variety of neurotrophic molecules that can support MN survival in vivo and in vitro indicates that developing and postnatal MNs depend 
on a cooperation of these molecules that is so far not fully understood (Oppenheim, 1996; Holtmann et al., 2005). NTFs promoting $\mathrm{MN}$ survival in vivo and in vitro belong to different gene families and activate several signaling pathways (Soler et al., 1999; Dolcet et al., 2001). To maintain MNs alive in culture, we (Gou-Fabregas et al., 2009) and others (Arce et al., 1999) use a cocktail of NTFs to achieve the maximal cell survival rates. We analyze the intracellular mechanisms involved in MN survival induced by the NTF cocktail. Using a primary culture of embryonic mouse MNs and reducing the protein level of several NF- $\kappa \mathrm{B}$ family members, we demonstrate that the NF- $\kappa \mathrm{B}$ canonical pathway is involved in the survival process. We show an apoptotic cell death effect on MNs when the canonical pathway is blocked; cell death is abolished when the antiapoptotic $\mathrm{Bcl}-\mathrm{x}_{\mathrm{L}}$ protein is overexpressed or when proapoptotic Bax protein is reduced. Finally, we show that RelA knockdown causes CREB and Smn protein reduction, suggesting the involvement of NF- $\kappa$ B signaling in the regulation of these proteins.

\section{Materials and Methods}

Mouse MN isolation and culture. MN cultures were prepared from embryonic day 12.5 (E12.5) CD1 male and female mouse spinal cords, essentially as described previously (Arce et al., 1999; Gou-Fabregas et al., 2009), with modifications. Briefly, mouse embryo spinal cords were dissected and the dorsal half removed. Ventral cords were chopped and incubated in GHEBS buffer ( $137 \mathrm{~mm} \mathrm{NaCl}, 2.7 \mathrm{~mm}$ $\mathrm{KCl}, 22.2 \mathrm{~mm}$ glucose, $25 \mathrm{~mm}$ HEPES buffer, $\mathrm{pH} 7.4$, and $20 \mathrm{IU} / \mathrm{ml}$ penicillin plus $20 \mathrm{mg} / \mathrm{ml}$ streptomycin) containing trypsin (Sigma; final concentration $0.025 \%$ ) for $10 \mathrm{~min}$ at $37^{\circ} \mathrm{C}$, followed by mechanical dissociation, then collected under a $4 \%$ bovine serum albumin (BSA) cushion. The largest cells were isolated by centrifugation $(10 \mathrm{~min}$ at $520 \times g)$ on an Iodixanol (OptiPrep, Axis-Shield) density gradient. Iodixanol solution (11.5\%) was freshly prepared in GHEBS. At the end of this procedure, cells were again centrifuged through a BSA cushion. The collected cells were pooled in a tube containing culture medium and plated at various densities (see MN culture and survival evaluation). Cultured MNs enriched by Iodixanol were clearly identified by morphological criteria (GouFabregas et al., 2009). All of the procedures were in accordance with the Spanish Council on Animal Care and approved by the University of Lleida Advisory Committee on Animal Services.

Isolated MNs were plated in four-well tissue culture dishes (Nunc, Thermo Fisher Scientific) for survival experiments (15,000 neurons per well), or for Western blot analysis (70,000 cells per well). Wells were coated with polyornithine/laminin as described previously (Soler et al., 1998). Culture medium was Neurobasal (Invitrogen) supplemented with B27 (Invitrogen), horse serum (2\% v/v), L-glutamine $(0.5 \mathrm{~mm})$, and 2-mercaptoethanol (25 $\mu \mathrm{M})$.

A

$B$
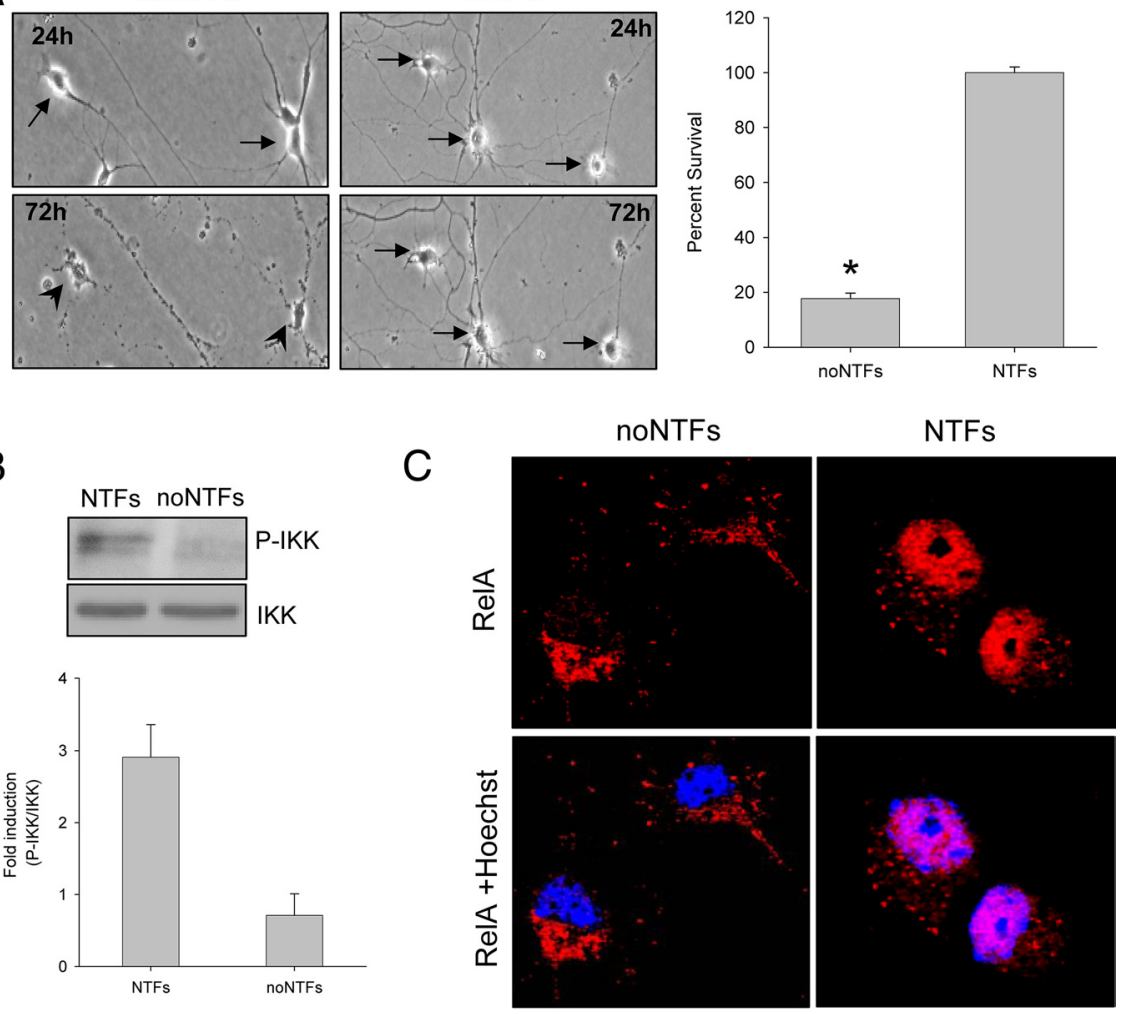

D LY+NTFs NTFs noNTFs
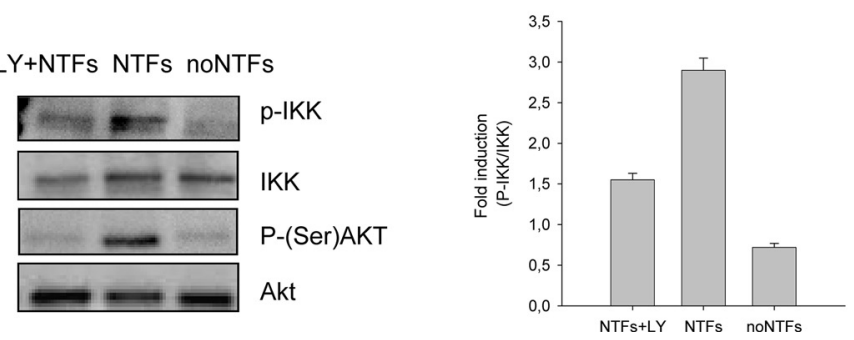

Figure 1. Effect of NTFs on IKK phosphorylation and $p 65$ nuclear translocation. $\boldsymbol{A}$, Representative microscopy images of 24 and $72 \mathrm{~h}$ cultured spinal cord MNs in the presence (right panels) or the absence (left panels) of NTFs (10 ng/ml CNTF, GDNF, HGF, BDNF). Arrows indicate surviving cells. Arrowheads indicate dying cells. The percentage of cell survival was measured as described in Materials and Methods. Values of the graph are the mean of the percentage of cell survival for each condition of nine wells from three independent experiments \pm SEM (error bars). Asterisk indicates significant differences between data from the experiments using one-way ANOVA test and Bonferroni's post hoc multiple comparisons ( ${ }^{*} p<0.01$ ). B , Protein extracts of NTF-stimulated (10 $\mathrm{min}$ ) or nonstimulated cultures were probed with an anti-phospho-IKK (P-IKK) antibody by Western blot analysis. Membranes were stripped and reprobed with an antibody against IKK, used as a loading control. C, Cells were cultured in the presence or the absence of the NTF cocktail. Twenty-four hours later, cultures were fixed and immunofluorescence was performed using an anti-RelA antibody. Representative confocal images of p65 (red) and Hoechst nuclear staining (blue). D, MN cultures were stimulated with NTFs in the presence or the absence of $25 \mu \mathrm{M} \mathrm{LY} 294002$, or left untreated, and protein extracts were probed with P-IKK and anti-phospho-Ser473 Akt antibodies. LY294002 was pretreated for 45 min before NTF stimulation. Membranes were stripped and reprobed with an antibody against IKK or Akt, respectively. Graph values in $\boldsymbol{B}$ and $\boldsymbol{D}$ represent measures of phospho-IKK versus total IKK from three independent experiments \pm SEM.

Measures of MN survival and apoptotic cell death. MN survival evaluation was performed as described previously (Arce et al., 1999), with modifications. Briefly, cells were plated in complete medium containing a cocktail of recombinant NTFs ( $1 \mathrm{ng} / \mathrm{ml}$ BDNF, $10 \mathrm{ng} / \mathrm{ml} \mathrm{GDNF}$, and 10 $\mathrm{ng} / \mathrm{ml}$ CNTF; PeproTech). Three hours after plating, medium was replaced and complete medium containing lentiviral particles (see below) was added. Twenty hours later, medium was washed and fresh medium containing NTFs was added. Photomicrographs of different microscopic areas from each dish were performed (four central areas per well, three wells for each condition), and we counted the number of large phasebright neurons with long neurite processes present in the photomicrographs. The number of cells present in each dish was considered our 
initial 100\%. Photomicrographs and counts were performed at indicated times in the same microscopic areas as the initial count. Survival was expressed as the percentage of cells counted with respect to the initial value $(100 \%)$. Survival experiments performed in nontransduced cultures were performed as described in text and figure legends.

For apoptotic nuclear morphology assessment, cells were fixed in $4 \%$ paraformaldehyde and $100 \%$ methanol, and stained with $0.05 \mu \mathrm{g} / \mathrm{ml}$ Hoechst 33258 for $30 \mathrm{~min}$ at room temperature. Uniformly stained nuclei were scored as healthy, viable cells, whereas condensed or fragmented nuclei were considered as dead cells. For survival and cell death quantification experiments, we used an Olympus IX71 microscope equipped with epifluorescence optics.

Immunofluorescence of RelA nuclear translocation. To determine RelA translocation to the nucleus, cells were incubated for $24 \mathrm{~h}$ in the presence or absence of the NTF cocktail. The cultures were fixed in $4 \%$ paraformaldehyde and $100 \%$ methanol, incubated overnight at $4^{\circ} \mathrm{C}$ with a polyclonal anti-RelA antibody (1:100; Santa Cruz Biotechnology), and further incubated with an anti-rabbit secondary antibody conjugated with Alexa Fluor 488 (Invitrogen) for $1 \mathrm{~h}$ at room temperature protected from light. Nuclear staining was obtained with Hoechst 33258, as described above. Micrographs were obtained using a FluoView 500 Olympus confocal microscope.

Western blot analysis. Western blot analysis was performed as described previously (Pérez-García et al., 2004). Cells were rinsed in icecold PBS, pH 7.2, after stimulation or lentiviral transduction. Total cell lysates were collected and resolved in SDS-polyacrylamide gels and transferred onto polyvinylidene difluoride Immobilon-P transfer membrane filters (Millipore), using a GE Healthcare semidry Trans-Blot according to the manufacturer's instructions. The membranes were blotted with the specific antibodies: anti-Bax (1:1000); anti-Cleaved Caspase-3 (1: 1000); anti-RelA (1:1000); anti-phospho-IKK (1:1000); anti-Ser 32/36 $\mathrm{I} \kappa \mathrm{B} \alpha$ (1:500); anti-phospho-serine 473-Akt (1:1000); anti-CREB (1: 1000); or anti-phospho-CREB (1:1000) from Cell Signaling Technology; anti-Bcl- $\mathrm{x}_{\mathrm{L}}$ (1:3000) or anti-Smn (1:5000) from BD Transduction Laboratories; anti-IKK $\beta$ (1:1000) or anti-IKK $\alpha$ (1:1000) from Calbiochem; anti-RelB (1:1000) (C-19), anti-I $\kappa \mathrm{B} \alpha(1: 1000)$, or anti-Akt (1:1000) from Santa Cruz Biotechnology; or anti-Bim (1:500) from Stressgen, following the instructions of the providers. Unless stated otherwise, to control the specific protein content per lane, membranes were reprobed with a monoclonal anti- $\alpha$-Tubulin antibody (1:50000, Sigma), as described by the provider. Blots were developed using the Super Signal chemiluminescent substrate (Pierce) or the ECL Advance Western Blotting detection kit (GE Healthcare).

NF- $\kappa$ B inhibitor SN50, the inactive control peptide SN50M, and the proteasome inhibitor MG132 were purchased from Calbiochem. The PI 3-kinase inhibitor LY294002 was from Tocris Bioscience.

Plasmids and production of lentiviral particles. Lentiviral-based vectors for RNA-interference-mediated gene silencing (FSVi) were performed as described previously (Encinas et al., 2008). FSVi consisted of a U6 promoter for expression of short-hairpin RNAs (shRNAs) and the Venus variant of green fluorescent protein (GFP) under the control of an SV40 promoter for monitoring transduction efficiency. Lentiviruses were propagated in HEK293T cells using the polyethyleneimine (PEI, Sigma) cell transfection method. Twenty micrograms of the above plasmids containing the shRNAs or the empty vector, $13 \mu \mathrm{g}$ of pSPAX2, and $7 \mu \mathrm{g}$ of pM2G were transfected to HEK293T cultures. Cells were allowed to produce lentivirus for $4 \mathrm{~d}$. Then the medium was centrifuged at $1200 \times g$ for $5 \mathrm{~min}$, and the supernatant was filtered using a $45 \mu \mathrm{m}$ filter. The medium containing the lentiviruses was stored at $4^{\circ} \mathrm{C}$. Biological titers of the viral preparations, expressed as the number of transducing units per milliliter (TU/ml), were determined by transducing HEK293T cells in limiting dilutions. After $48 \mathrm{~h}$, the percentage of GFP-positive cells was measured, and viruses at $4 \times 10^{5}$ to $1 \times 10^{6} \mathrm{TU} / \mathrm{ml}$ were used for the experiments. For lentiviral transduction, MNs were plated in four-well dishes and $2 \mathrm{~h}$ later the medium containing lentivirus (2 TU/cell) was added. The medium was changed $20 \mathrm{~h}$ later and infection efficiency was monitored in each experiment by directly counting GFP-positive cells. The frequency of infection rose $99 \%$. RNA interference efficiency was monitored by Western blot analysis using specific antibodies.
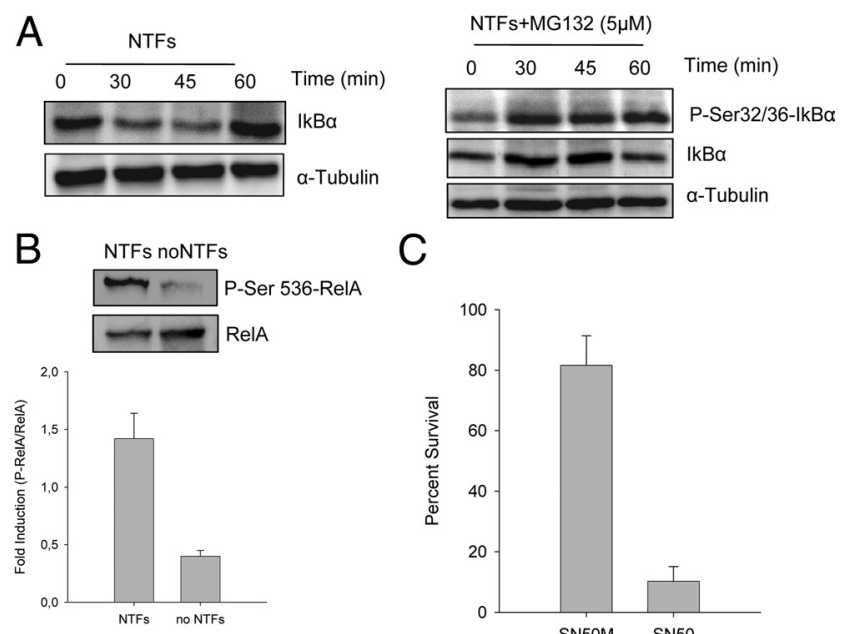

C

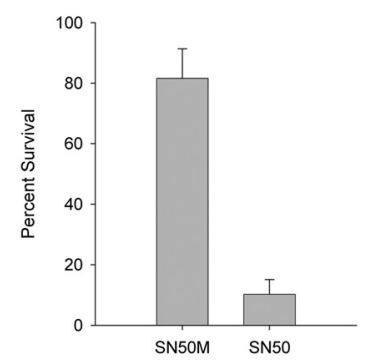

Figure 2. Effect of NTFs on $\mid \kappa B$ and $p 65$ phosphorylation. $A$, Representative Western blots for total IkB $\alpha$ (left) and phospho-Ser $32 / 36 \mathrm{lkB} \alpha$ (right) in protein extracts of MNs treated with NTFs in the presence or the absence of $5 \mu \mathrm{M}$ MG132. Time 0 indicates the basal level of total or phospho-lkB $\alpha$. B, Representative Western blot for phospho-Ser536 RelA and total RelA in protein extracts of cultures stimulated $(20 \mathrm{~min})$ or nonstimulated with NTFs. Graph indicates the increase of RelA phosphorylation compared with the total RelA protein. C, MNs were cultured in the presence of NTFs and the NF $\kappa$ B inhibitor SN50 $(20 \mu \mathrm{M})$ or its inactive control SN50M (20 $\mu \mathrm{M})$. Cell survival was evaluated $3 \mathrm{~d}$ after treatment. Graph values are the mean of the percentage of cell survival for each condition of nine wells from three independent experiments \pm SEM (error bars). Asterisk indicates significant differences between data from the experiments using one-way ANOVA test and Bonferroni's post hoc multiple comparisons ( $\left.{ }^{*} p<0.001\right)$.

The following sequences were used for generation of shRNAs: Bax: 5'-GCAGCTGACATGTTTGCTGAT-3'; IKK $\alpha$ : 5' -CAGGCTCTTTCAGGGCAT-3'; IKK $\beta 1$ : $5^{\prime}$-GCTGCACATTTGAATCTGTAT-3'; IKK $\beta 2$ : 5'-GCTCTTAGATACCTTCATGAA-3'; scrambled IKK control: 5' GCTCTCTTGAAGGTTGATGTA-3'; RelA: $5^{\prime}$-AGATCTTGAGCTCGGCAGTG-3'; RelB: 5'-GCATGCGCTTCCGCTACGAGT-3'. shRNAs of IKKs and RelA have been described by Dolcet et al. (2006).

Statistical analysis. All experiments were performed at least three times. Values were expressed as mean \pm SEM. The data obtained from the independent experiments were used for statistical analysis. We used one-way ANOVA to assess survival differences between groups for variable treatment. If the ANOVA test was statistically significant, we performed post hoc pairwise comparisons using the Bonferroni test; $p$ values lower than 0.05 were considered significant.

\section{Results}

\section{Neurotrophic factor stimulation induces NF- $\mathrm{B}$ pathway activation on spinal cord MNs}

Addition of NTFs to culture medium induces neuronal survival through the activation of intracellular pathways. One of the well known pathways activated after NTFs stimulation is the PI 3-kinase/Akt [for review, see Airaksinen and Saarma (2002) and Chao (2003)]. However, NTFs can also activate other pathways that are crucial for the neuronal physiology. In some neuronal populations, the NF- $\kappa \mathrm{B}$ pathway is activated by cytokines and is responsible for cell survival and/or neurite outgrowth (Maggirwar et al., 1998; Gallagher et al., 2007). Because no information exists about the involvement of the NF- $\kappa \mathrm{B}$ pathway mediating MN survival, we decided to analyze this subject in our MN model. Spinal cord MNs respond to a variety of NTFs; requirements for these factors vary depending on the $\mathrm{MN}$ subpopulations and the developmental period (Holtmann et al., 2005). Our previous work (our unpublished results and Gou-Fabregas et al., 2009) and that of others (Arce et al., 1999) showed that using a cocktail of NTFs enhanced MN survival compared to the survival rate 
obtained by each NTF separately. Thus, we decided to analyze the role of the NF- $\kappa \mathrm{B}$ pathway when optimal survival conditions were present in the culture medium. The maximal survival level obtained was when we added to the medium the following cocktail: $1 \mathrm{ng} / \mathrm{ml}$ BDNF, 10 $\mathrm{ng} / \mathrm{ml} \mathrm{CNTF}$, and $10 \mathrm{ng} / \mathrm{ml}$ GDNF (our unpublished results and Fig. 1).

After $72 \mathrm{~h}$ in the presence of NTFs, $\sim 100 \%$ of MNs were alive; only $\sim 20 \%$ of MNs survived in the absence of NTFs (Fig. 1). To analyze the ability of NTFs to activate the NF- $\kappa \mathrm{B}$ pathway, we tested both IKK phosphorylation and RelA nuclear translocation. The IKK protein complex becomes phosphorylated and activated in response to the stimuli that induce $\mathrm{NF}-\kappa \mathrm{B}$ pathway activation (Delhase et al., 1999). Using an anti-phospho-IKK antibody (PIKK), we evaluated IKK phosphorylation after 10 min of NTFs stimulation. We observed that NTF stimulation increases IKK phosphorylation level as compared to nonstimulated cultures, indicating that NTFs were able to induce IKK phosphorylation (Fig. $1 B$ ).

After IKK and $\mathrm{I} \kappa \mathrm{B}$ phosphorylation, $\mathrm{NF}-\kappa \mathrm{B}$ complex is released, relocates to the nucleus, and binds to the $\kappa \mathrm{B}$ DNA elements, resulting in gene induction or gene repression (Perkins, 2007). To analyze the effect of NTF treatment on RelA translocation to the nucleus, MNs were cultured for $24 \mathrm{~h}$ in the presence or absence of NTFs. Using an anti-RelA antibody, immunofluorescent confocal images showed that NTF treatment induced nuclear relocation of RelA (Fig. 1C). However, in the absence of NTFs, RelA is maintained primarily in the cytoplasm. The percentage of MNs with RelA localized in the nucleus of NTF-treated cultures was $85 \pm 6.6 \%$, whereas in the absence of NTFs, the percentage of cells with RelA localized in the nucleus was only $17.3 \pm 3.3 \%$. Together, these results indicate that NTF treatment induces NF- $\kappa \mathrm{B}$ pathway activation in MNs. We mentioned above that one of the main intracellular pathways related to NTF-induced neuronal survival is the PI 3-kinase/Akt. To examine whether this pathway has a role in NF- $\kappa \mathrm{B}$ activation in MNs, we used the PI 3-kinase inhibitor LY294002 and analyzed IKK phosphorylation by Western blot. When $25 \mu \mathrm{M}$ LY294002 was present in the culture medium, the level of IKK phosphorylation was 50\% reduced when compared to the NTF-treated controls (Fig. 1D). This result shows that PI 3-kinase blockade results in IKK phosphorylation decrease, suggesting the involvement of this pathway in NF- $\kappa \mathrm{B}$ activation after NTF treatment.

\section{NTFs induce canonical NF- $\kappa$ B pathway activation}

At least two pathways to activate NF- $\kappa \mathrm{B}$ exist: canonical and noncanonical. The canonical pathway depends upon the phosphorylation status of the two kinases IKK $\alpha$ and IKK $\beta$, which
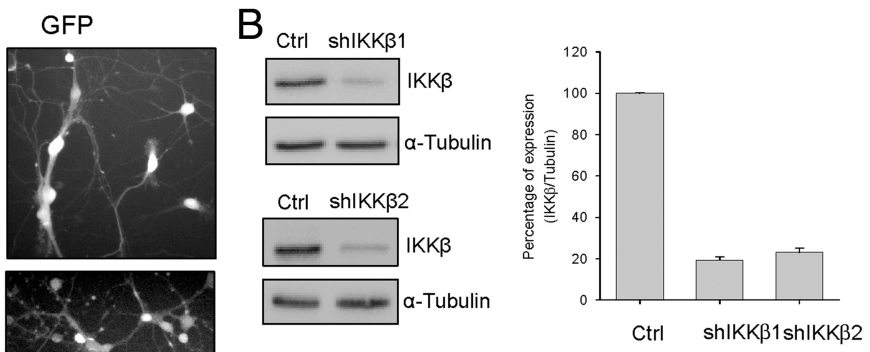

Figure 3. Effect of IKK $\beta$ or IKK $\alpha$ knockdown on MN survival in the presence of NTFs. Mouse MNs were transduced with lentivirus containing the shIKK $\beta 1$, shIKK $\beta 2$, shlKK $\alpha$, or empty vector (Ctrl) constructs. $\boldsymbol{A}$, Representative microscopy images of $3 \mathrm{~d}$ shIKK $\beta$-, shlKK $\alpha-$, or Ctrl-transduced cultures: phase contrast (left) and GFP (right). GFP indicates green fluorescent protein-expressing cells in the values are the mean of the percentage of IKK $\beta$ or IKK $\alpha$ protein level in MNs transduced with shIKK $\beta 1$, shIKK $\beta 2$, or shlKK $\alpha$ 列

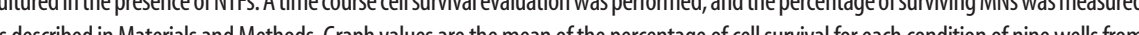
three independent experiments \pm SEM (error bars). Asterisk indicates significant differences between data from the experiments using one-way ANOVA test and Bonferroni's posthoc multiple comparisons ( ${ }^{*} p<0.001$ ). Bottom, Representative Western blots of IKK $\alpha$ or IKK $\beta$ protein decrease at different time points after shIKK $\alpha$ or shIKK $\beta$ lentiviral transduction.

together with the regulatory subunit NEMO/IKK $\gamma$ constitute the catalytic part of the IKK complex; activation of the noncanonical pathway depends on the phosphorylation of an IKK $\alpha$ homodimer. The most frequently observed is the canonical pathway, which is induced in response to various stimuli. This pathway is typified by the rapid phosphorylation of the IKK complex, I $\kappa \mathrm{B}$ degradation, the release of the RelA/p50 complex, and its translocation to the nucleus (Li et al., 1999; Perkins, 2007). To analyze the activation of the canonical pathway in our experimental model, we first examined whether NTFs induced I $\kappa$ B endogenous protein reduction. Western blots showed a clear decrease in total $\mathrm{I} \kappa \mathrm{B}$ protein after $30-45 \mathrm{~min}$ followed by a characteristic resynthesis of $\mathrm{I} \kappa \mathrm{B} \alpha$ that was evident after $60 \mathrm{~min}$ of NTF treatment (Fig. 2A). 

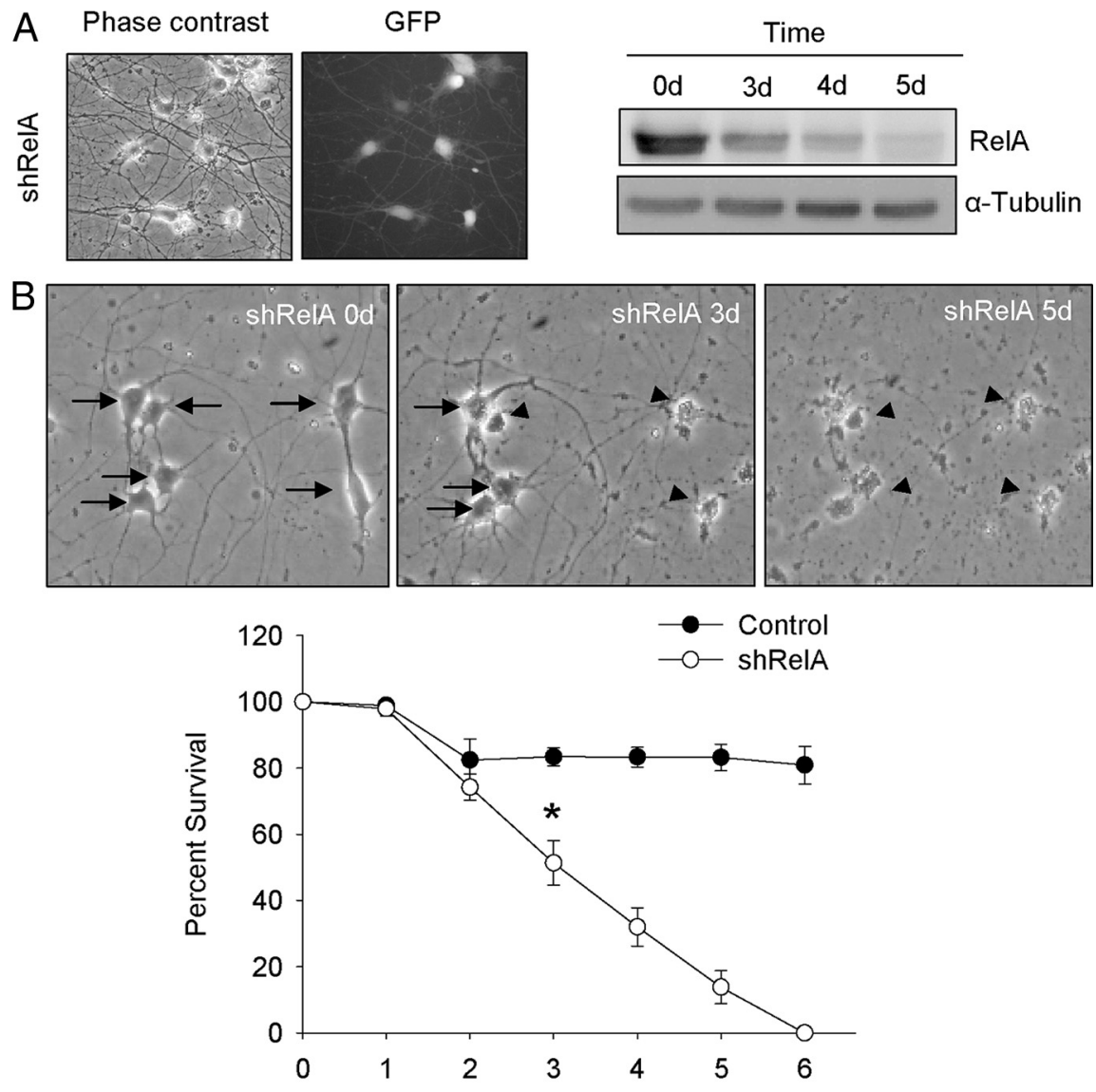

Time (days)

Figure 4. RelA knockdown reduced NTF-promoted MN survival. A, Representative microscopy images of $3 \mathrm{~d}$ shRelA-transduced MNs: phase contrast (left) and GFP (right) of the same microscopic field. Western blot analysis of RelA protein levels after 0, 3, 4, or $5 \mathrm{~d}$ of shRelA transduction. Protein extracts were collected at the different time points and analyzed using an antibody against RelA protein. Membranes were reprobed with an antibody against $\alpha$-Tubulin, used as a loading control. $\boldsymbol{B}$, Representative microscopy images of the same microscopic field of 0,3 , or $5 \mathrm{~d}$ shRelA-transduced cultures of MNs. Arrows indicate surviving cells. Arrowheads indicate dying or dead cells. The graph in $\boldsymbol{B}$ represents the percentage of surviving MNs at several time points after shRelA or empty vector transduction, as described in Materials and Methods. Graph values are the mean of the percentage of cell survival for each condition of nine wells from three independent experiments \pm SEM (error bars). Asterisk indicates significant differences between data from the experiments using one-way ANOVA test and Bonferroni's post hoc multiple comparisons ( $\left.{ }^{*} p<0.001\right)$.

In the canonical pathway, NF- $\kappa \mathrm{B}$ is activated by phosphorylation of $\mathrm{I} \kappa \mathrm{B} \alpha$ on serine residues 32 and 36 (Hayden and Ghosh, 2004). To ascertain whether NTFs increases $I \kappa B \alpha$ phosphorylation in these serine residues, protein extracts from MNs treated with NTFs for times ranging from 30 to 60 min were analyzed by Western blot and probed with an anti-I $\kappa$ B phosphoserine 32/36 antibody. To observe better $I \kappa \mathrm{B}$ phosphorylation, we avoid the proteasome-mediated degradation of $\mathrm{I} \kappa \mathrm{B}$ by adding the proteasome inhibitor MG132 in the culture medium. As we show in Figure $2 A$, NTFs promoted a marked increase in phosphoserine $\mathrm{I} \kappa \mathrm{B} \alpha$ within $30 \mathrm{~min}$, confirming the activation of the canonical $\mathrm{NF}-\kappa \mathrm{B}$ signaling pathway.

Finally, we also analyzed RelA serine phosphorylation using an anti-phosphoserine 536 RelA antibody. This serine phosphorylation in RelA is mediated by IKK complex (Perkins, 2007). Twenty minutes after NTF stimulation, we observed a clear increase of phosphor-serine 536-RelA compared to the nonstimulated controls (Fig. 2B). All these findings together strongly suggest the activation by NTFs of the canonical NF- $\kappa$ B signaling pathway in MNs.

\section{Effect of IKK $\beta$ or IKK $\alpha$ inhibition on the NTF-induced MN survival}

To assess the requirement for NF- $\kappa \mathrm{B}$ signaling in the NTF-induced MN survival, we inhibited several different steps in the NF- $\kappa \mathrm{B}$ signaling network. First, we pharmacologically inhibited the NF- $\kappa \mathrm{B}$ pathway using the SN50 inhibitor peptide, a cell-permeable peptide that blocks the nuclear localization sequence of p50 (Lin et al., 1995). To this end, cultures were treated with NTFs and $20 \mu \mathrm{M} \mathrm{SN50}$ or its inactive control peptide SN50M, and $3 \mathrm{~d}$ later $\mathrm{MN}$ survival was evaluated. The presence of NF- $\kappa \mathrm{B}$ inhibitor in the culture medium significantly decreased MN survival induced by NTF treatment when compared with its inactive control (Fig. 2C).

To further assess the relevance of the NF- $\kappa \mathrm{B}$ pathway to mediating NTFinduced MN survival, we performed lentiviral-based knockdown of IKK $\beta$ and IKK $\alpha$. First, we generated two shRNA sequences targeting two specific sites of mouse IKK $\beta$ (shIKK $\beta 1$ and $\operatorname{shIKK} \beta 2$ ) and generated lentiviral particles containing the shRNAs. MNs were isolated from E12.5 mouse embryos and maintained in the presence of the NTFs. Two hours after plating, culture medium was changed and medium containing NTFs and lentivirus of shIKK $\beta 1$ or shIKK $\beta 2$ or shRNA empty vector control was added. Twenty hours later, the medium was washed and replaced by fresh medium supplemented with NTFs. As shown in Figure $3 A$, the frequency of transduction rose to $99 \%$ of the cells present in the culture dish (GFPpositive cells monitored by fluorescence microscope). After $5 \mathrm{~d}$, Western blot analysis of cultures transduced with lentivirus carrying shIKK $\beta 1$ or shIKK $\beta 2$ exhibited a strong reduction of IKK $\beta$ protein compared with the control cultures transduced with the empty vector (Ctrl) (Fig. 3B). The low levels of IKK $\beta$ were maintained throughout the experiment (data not shown). MNs transduced with these lentiviral constructions were used for a time course survival analysis of the effect of endogenous IKK $\beta$ knockdown in NTF-supplemented cultures. To assess cell survival, we calculated the percentage of cells present in the tissue culture dish at various days after transduction compared to the number of cells counted in the same microscopic fields at the beginning of the experiment. Cultures transduced with the empty vector control showed a level of cell survival $\sim 100 \%$ from day 1 to day 6 (end of the experiment) (Fig. $3 B$ ). Control survival experiments using a scrambled RNA control vector for the shIKK knockdown were also performed. When cells were transduced with the scrambled shIKK, cell survival was similar to the empty vector controls ( $3 \mathrm{~d}$ after transduction: $86.3 \pm 4.8 \%$ and $93.3 \pm 2.8 \%$, respectively; $5 \mathrm{~d}$ after transduction: $82.2 \pm 0.5 \%$ and $80.8 \pm 3.8 \%$, respectively). Time course survival experiments demonstrated that when IKK $\beta$ protein level was reduced, cell survival dramatically decreased from day 4 to 
day $6(80.6 \pm 5.5 \%$ and $6.9 \pm 1.7 \%$, respectively) (Fig. $3 B$ ). We also generated a shRNA sequence targeting specific sites of mouse IKK $\alpha(\operatorname{shIKK} \alpha)$. After $5 \mathrm{~d}$ of lentiviral transduction, IKK $\alpha$ protein level was reduced in shIKK $\alpha$ cultures compared to empty vector control cells (Fig. $3 A$ ), and this reduction was maintained through the end of day 6 (data not shown). We also performed survival experiments after IKK $\alpha$ protein knockdown, following the same cell-counting protocol described above and in Materials and Methods. Results showed that MN survival was compromised when endogen IKK $\alpha$ was reduced. The percentage of survival of shIKK $\alpha$ cultures decreased gradually from day 1 to day 6 (Fig. 3B). Western blots of IKK protein reduction revealed that IKK $\beta$ dropped abruptly at day 5 after transduction and IKK $\alpha$ decreased gradually from the day 2 . Together, all these results demonstrated that both IKK $\beta$ and IKK $\alpha$ contribute to NTF-induced MN survival.

RelA, but not RelB, inhibition causes cell death in NTF-maintained MNs

Active binding to specific DNA sequences is performed by heterodimers or homodimers of NF- $\kappa \mathrm{B}$ subunits. The most prominent and extensively studied dimer is that of RelA (also called p65) and p50, which is activated in the canonical pathway; RelB and p52 form a dimer that participates in the noncanonical scheme (Perkins, 2007). To determine which of these pathways is involved in MN survival, we analyzed the effect of RelA or RelB knockdown. We generated shRNA targeting specific sites of mouse RelA (shRelA) or RelB (shRelB) sequences. As shown in Figures 4 and 5, the frequency of transduction was near $100 \%$ of the cells present in the culture (GFP-positive cells monitored by fluorescence microscopy). When analyzed by Western blot using specific antibodies, the level of RelA or RelB proteins in shRelA- or shRelB-transduced cultures, respectively, was clearly reduced in comparison to the empty vector control cells. Figure $4 \mathrm{~A}$ shows a time course analysis of RelA protein reduction; and Figure $5 C$ shows RelB protein reduction (day 5 after transduction). We performed survival experiments following the same protocol described above. Reduction of endogen RelA protein caused MN cell death (Fig. 4B); nevertheless, RelB protein knockdown had no effect on MN survival (Fig. 5C). After $6 \mathrm{~d}$ of transduction, no surviving cells were found in shRelAtransduced cultures, whereas in shRelB at the same time period the percentage of cell survival was similar to empty vector control cultures ( $\sim 90 \%)$. These results strongly suggest that NTFs induce MN survival through activation of the NF- $\kappa \mathrm{B}$ canonical pathway, but not by the noncanonical pathway. The activation of the noncanonical pathway was shown by Western blot using an antibody against the p100 and the cleaved form p52. When cells were stimulated by NTFs, we observed the presence of a band corresponding to $\mathrm{p} 52$, whereas in non-NTF-stimulated protein extracts, p52 was absent in three independent experiments (Fig. $5 A$ ). Thus we demonstrated that even though the noncanonical

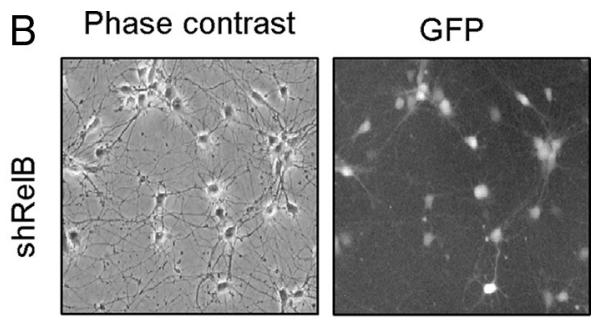

Ctrl shRelB

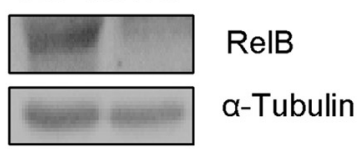
a-Tubulin
Time (days)
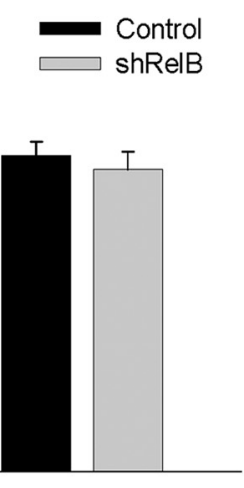

6

Figure 5. RelB protein is not implicated in mouse MNs survival. $\boldsymbol{A}$, Representative Western blot for $\mathrm{p} 100 / \mathrm{p} 52$ in protein extracts of cultures stimulated (20 $\mathrm{min}$ ) or nonstimulated with NTFs. The same membrane was reprobed with an antibody against a-Tubulin, used as a loading control. B, Microscopic images of 5 d shRelB-transduced MNs: phase contrast and GFP (left and right, probed with an anti-RelB antibody by Western blot; the membrane was reprobed with an antibody against $\alpha$-Tubulin, used as a loading control. C, Cell survival was evaluated at 3 or $6 \mathrm{~d}$ after shRelB or control transduction. Graph represents the mean of the percentage of cell survival for each condition of nine wells for three independent experiments \pm SEM (error bars).

pathway is activated by NTFs, its activation is not involved in the survival-promoting effect of these factors on MNs.

\section{Inhibition of the NF- $\kappa \mathrm{B}$ pathway causes apoptotic cell death}

Trophic factor deprivation induces apoptotic cell death in MNs (Soler et al., 1999; Dolcet et al., 2001). It is also known that in some neuronal models, inhibition of NF- $\kappa \mathrm{B}$ activation induces apoptosis (Piccioli et al., 2001); and NF- $\kappa \mathrm{B}$ regulates antiapoptotic gene transcription (Tian et al., 2005). To determine whether $\mathrm{NF}-\kappa \mathrm{B}$ pathway inactivation induces apoptotic cell death in our cultured cells, we analyzed both the presence of apoptotic nuclei and the activity of Caspase-3 as indicators of classical apoptosis. To this end, MNs were transduced using the following lentiviral constructs: shIKK $\beta$, shIKK $\alpha$, shRelA, or the empty vector control; $24 \mathrm{~h}$ later, medium containing lentiviral particles was washed and replaced by fresh medium containing NTFs. Five days later, we measured Caspase- 3 activity by Western blot using a specific antibody (Fig. 6A). As expected, shIKK $\beta-$, shIKK $\alpha-$, and shRelA-transduced cultures showed an increase of the activation-specific Caspase-3 fragment (p17). Control cultures also displayed activation of Caspase-3 when deprived of NTFs (data not shown).

To further analyze the apoptotic origin of the cell death observed, we counted the number of nuclei showing apoptotic morphology, using Hoechst 33258 staining (Fig. 6B). After $5 \mathrm{~d}$ of transduction, the percentage of apoptotic cells was increased in shIKK $\beta$, shIKK $\alpha$, and shRelA compared to the empty vector control treatment. Around $50 \%$ of the cells that received shIKK $\beta$ showed this particular morphology, which was the highest pro- 
A

\section{Ctrl shIKK $\beta$}

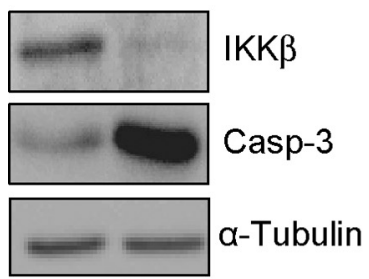

B

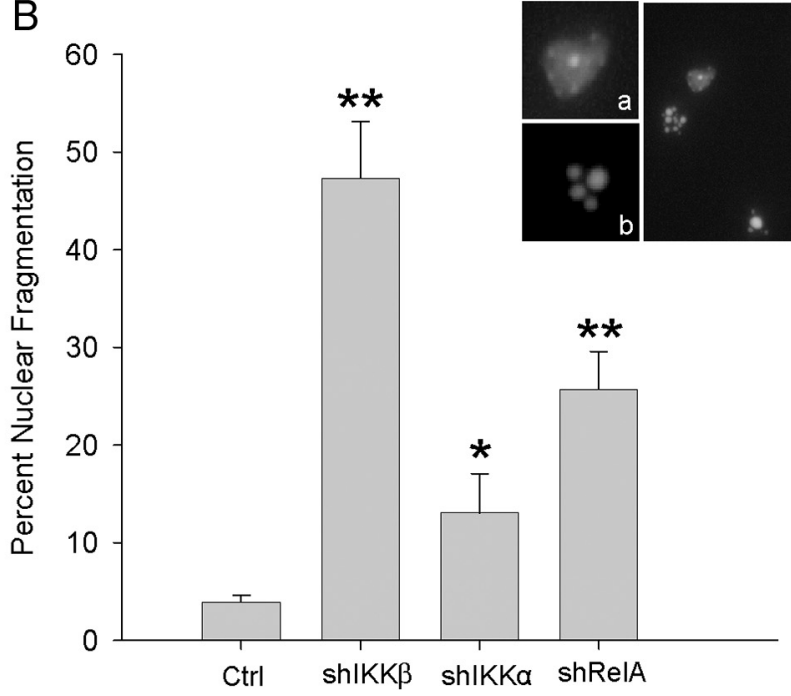

Ctrl shRelA

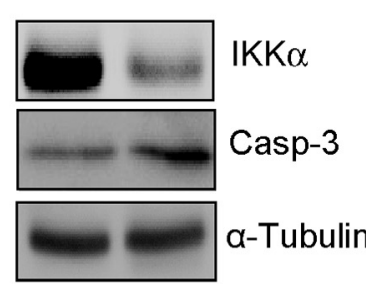

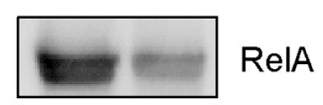

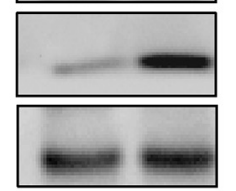

Casp-3

a-Tubulin

1995), we decided to overexpress human Bcl- $\mathrm{x}_{\mathrm{L}}\left(\mathrm{hBcl}-\mathrm{x}_{\mathrm{L}}\right.$; kindly provided by Dr. J.X. Comella, Institut de Recerca Hospital Vall d'Hebron, Barcelona, Spain) in our cell model. Thus, shIKK $\beta$, $\operatorname{shIKK} \alpha$, shRelA, or the empty vector control MN cultures were cotransduced with a lentiviral vector carrying an expression construct containing the human $B c l-x_{L}$ gene. Twenty hours after cotransduction, medium containing lentiviral particles was washed and replaced by fresh medium containing NTFs. By Western blot analysis, we observed that $\mathrm{Bcl}-\mathrm{x}_{\mathrm{L}}$ was overexpressed after $5 \mathrm{~d}$ of lentiviral transduction (Fig. 7). To determine the effect of $\mathrm{Bcl}-\mathrm{x}_{\mathrm{L}}$ overexpression in these cultures, survival experiments were performed after 3 and $5 \mathrm{~d}$ as described above. As observed in Figure $7 A, \mathrm{Bcl}-\mathrm{x}_{\mathrm{L}}$ significantly rescued cells from the death effect caused by IKK $\beta$, IKK $\alpha$, or RelA protein level reduction.

To establish whether NTF cocktail increased $\mathrm{Bcl}-\mathrm{x}_{\mathrm{L}}$ protein levels in our experimental paradigm, we analyzed changes of this protein in the presence or the absence of NTFs. MNs were isolated and cultured for different time periods. Western blot analysis of protein extracts obtained from cultures with or without NTFs was performed using a specific antibody against $\mathrm{Bcl}-\mathrm{x}_{\mathrm{L}}$. Results showed that the level of $B c l-x_{L}$ protein was clearly reduced in NTF-deprived cultures compared to NTF-treated cells (Fig. 7B). Thus, we proceeded to evaluate whether NF- $\kappa$ B pathway inhibition induces changes in Bcl- $\mathrm{x}_{\mathrm{L}}$ protein level. Western blot analysis of protein extracts from $5 \mathrm{~d}$ cultures trans-

Figure 6. IKK $\alpha$, IKK $\beta$, or RelA protein knockdown causes apoptotic cell death. $\boldsymbol{A}$, MNs were transduced with shIKK $\alpha$, shIKK $\beta$, shRelA, or empty vector (Ctrl) constructs and cultured in the presence of NTFs. After $5 d$, total cell lysates were analyzed by Western blot using an antibody against Cleaved Caspase-3. Membranes were reprobed with an antibody against $\alpha$-Tubulin, as a loading control; or antibodies against IKK $\alpha$, IKK $\beta$, or RelA as protein reduction control. $\boldsymbol{B}$, Five days after transduction, cultures were fixed and stained using Hoechst nuclear dye. Representative microscopy images of Hoechst staining of apoptotic ( $\boldsymbol{b}$ ) or nonapoptotic ( $\boldsymbol{a}$ ) nuclear morphology. The graph in $B$ represents the percentage of apoptotic nuclei present in shlKK $\alpha-$, shIKK $\beta-$, shRel $A-$, or Ctrl-transduced cultures; values are the mean of six wells for each condition from three independent experiments \pm SEM (error bars). Asterisk indicates significant differences between data from the experiments using one-way ANOVA test and Bonferroni's post hoc multiple comparisons $\left({ }^{*} p<0.05 ;{ }^{* *} p<0.001\right)$, compared to the empty vector control.

portion of apoptotic nuclei. shIKK $\alpha$ or shRelA treatment also induced a significant increase of apoptotic nuclei ( $13 \pm 3.9 \%$ and $25.7 \pm 3.9 \%$, respectively). Thus, when the NF- $\kappa$ B pathway was inactivated, the dying cells displayed apoptotic nuclear morphology, characterized by chromatin condensation and shrinkage of the nucleus even in the presence of NTFs. Control experiments of nontransduced cultures also showed an increase of the percentage of apoptotic nuclei when deprived (NTF-supplemented cultures: $7 \pm 1.2 \%$; NTF-deprived cultures: $55 \pm 3 \%$ ), confirming that in our system NTF deprivation induces apoptotic cell death. Together these results demonstrated that inhibition of the NF- $\kappa \mathrm{B}$ pathway induced apoptotic cell death in NTF-maintained MNs.

\section{Bcl- $\mathrm{x}_{\mathrm{L}}$ overexpression or Bax knockdown protects $\mathrm{MN}$ cell} death after IKK $\beta$, IKK $\alpha$, or RelA inhibition

We show here that NTFs induce MN survival through the NF- $\kappa \mathrm{B}$ pathway. When this pathway is blocked, the consequence is an apoptotic cell death even in the presence of NTFs. The same type of cell death is observed when MNs are deprived of NTFs (see above and our unpublished results). In other neuronal models, this apoptotic cell death could be blocked by overexpression or inhibition of antiapoptotic or proapoptotic proteins (respectively). Because $\mathrm{Bcl}-\mathrm{x}_{\mathrm{L}}$ is one of the strongest antiapoptotic proteins present in the nervous system (González-García et al., duced with shIKK $\beta$, shIKK $\alpha$, shRelA, or empty vector control did not show significant differences in $\mathrm{Bcl}-\mathrm{x}_{\mathrm{L}}$ protein, indicating that in our system NF- $\kappa \mathrm{B}$ inhibition neither increased nor reduced Bcl- $\mathrm{x}_{\mathrm{L}}$ (Fig. 7C). Finally, we checked whether Bcl- $\mathrm{x}_{\mathrm{L}}$ overexpression affected IKK $\beta$, IKK $\alpha$, or RelA protein expression in shRNAtransduced cultures. Protein extracts were analyzed by Western blot and results revealed that $\mathrm{Bcl}-\mathrm{x}_{\mathrm{L}}$ overexpression did not affect IKK $\beta$ or IKK $\alpha$ (Fig. $7 D$ ) or RelA (data not shown) protein level.

To further confirm that apoptosis was controlling the cell death process caused by NF- $\kappa$ B pathway blockade and that increasing the cellular antiapoptotic mechanisms could rescue $\mathrm{MNs}$ from death caused by NF- $\kappa \mathrm{B}$ inhibition, we reduced the levels of the proapoptotic member of the Bcl-2 family, Bax. Bax has been related to mitochondrial dysfunction and apoptosis (Wei et al., 2001). Thus, after plating, we transduced MNs with a shRNA targeting specific sites of mouse Bax sequence ( shBax) or left them untransduced; after $3 \mathrm{~d}$, cultures were cotransduced or transduced (respectively) with shIKK $\beta$, $\operatorname{shIKK} \alpha$, shRelA, or the empty vector control (considered as time 0 of the experiment; see diagram in Fig. 8). Using a specific antibody, we found that Bax protein level was significantly reduced after $3 \mathrm{~d}$ of shBax transduction. After 3 and $5 \mathrm{~d}$ of $\operatorname{shIKK} \beta, \operatorname{shIKK} \alpha$, or shRelA cotransduction, cell survival was evaluated as described in Materials and Methods (Fig. 8). 
Results showed that in cultures cotransduced with shBax and shIKK $\beta$ or shRelA (Fig. $8 A$ ) or shIKK $\alpha$ (data not shown), survival percentage was significantly increased compared with cultures with no Bax cotransduction. As described above for $\mathrm{Bcl}-\mathrm{x}_{\mathrm{L}}$ protein, IKK $\beta$ or RelA reduction did not change Bax protein level (Fig. $8 B$ ).

\section{Effect of NF- $\kappa$ B pathway inhibition on Bim protein level}

It has been demonstrated that during apoptosis, Bim, the BH3-only member of $\mathrm{Bcl}-2$ family, can directly or indirectly activate the proapoptotic Bax and the subsequent mitochondrial apoptotic pathway. Moreover, Bim displaces $\mathrm{Bcl}-\mathrm{x}_{\mathrm{L}}$ in the mitochondria and promotes Bax translocation during TNF $\alpha$-induced apoptosis (Zhang et al., 2008). In this context, we decided to analyze whether Bim protein levels changed when the canonical NF- $\kappa \mathrm{B}$ pathway was knocked down. Thus, MNs were transduced with shRelA, and protein extracts were collected $5 \mathrm{~d}$ after transduction. By Western blot analysis using an antibody against $\mathrm{Bim}_{\mathrm{EL}}$, we observed that Bim protein level increased in shRelA cultures compared with the empty vector control condition (Fig. $9 A$ ). These results strongly suggest that after canonical NF- $\kappa \mathrm{B}$ signaling inhibition, Bim increase can induce the apoptotic cell death observed.

\section{RelA knockdown causes Smn protein decrease}

Smn (survival motor neuron) protein is a ubiquitously expressed protein with nuclear and cytoplasm functions. Its deficiency causes the neurodegenerative disease spinal muscular atrophy. This disease is characterized by the specific loss of ventral horn spinal cord MNs (Sumner, 2006). Because the NF- $\kappa$ B pathway is involved in MN survival, we wanted to know whether the NF- $\kappa$ B signaling pathway might be affecting the Smn protein level. MNs were transduced with shRelA, and cell extracts were collected $4 \mathrm{~d}$ after transduction and analyzed by Western blot using a specific antibody against Smn. Results obtained showed that after RelA knockdown, Smn protein levels were reduced compared with the empty vector control cultures $38 \pm 6 \%$ and $100 \%$, respectively). It has been previously described that the transcription factor CREB (cAMP-response elementbinding) regulates Smn protein expression (Majumder et al., 2004). In this context, we decided to evaluate changes in CREB phosphorylation and protein level. MNs were transduced with shRelA, and $4 \mathrm{~d}$ later, cell extracts were collected. Western blot analysis using specific antibodies against CREB and phosphoCREB demonstrated that the endogenous CREB protein level was reduced (Fig. 9B). All these results together suggest that CREB and Smn protein expression is dependent on NF- $\kappa \mathrm{B}$ signaling pathway activity.
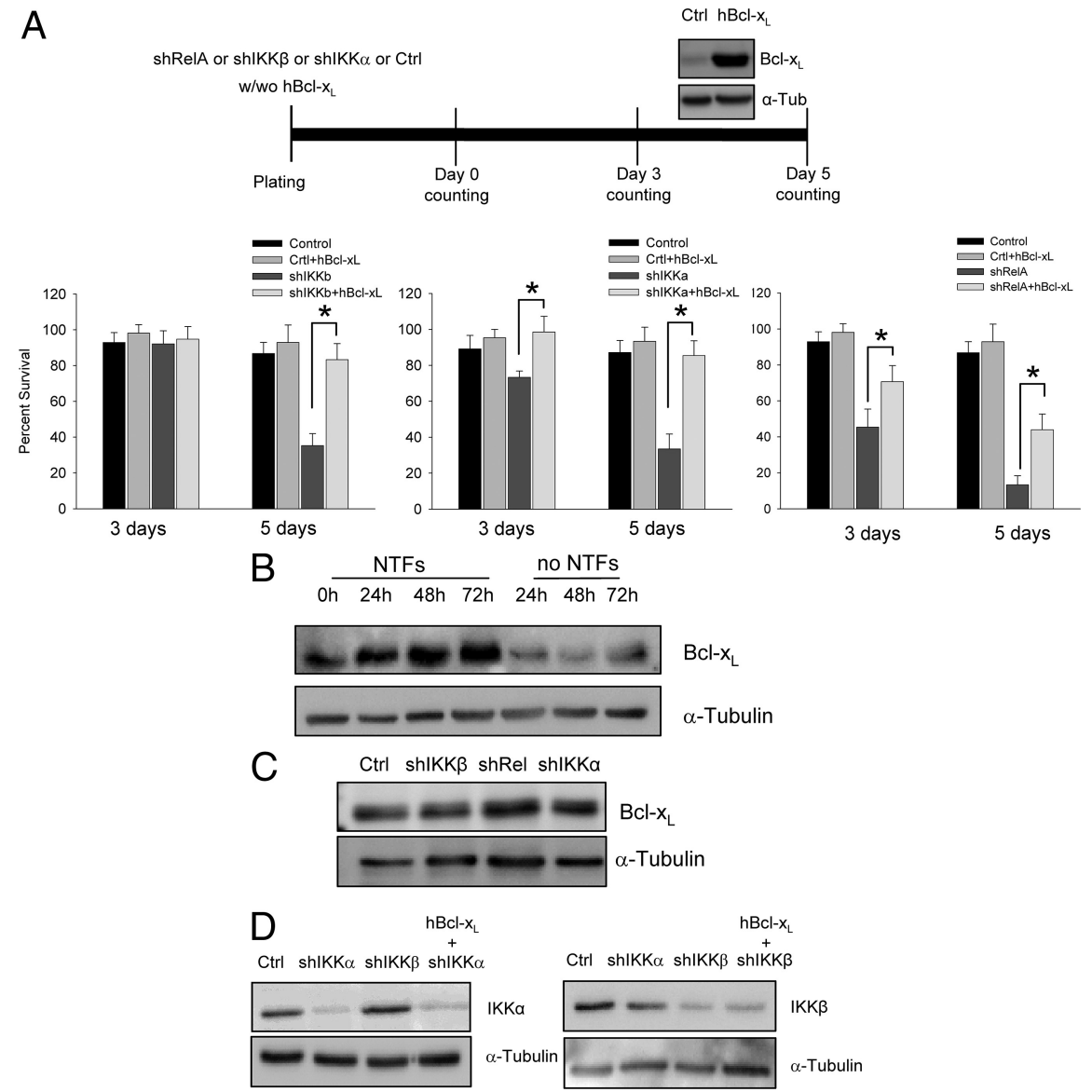

Figure 7. BCl- $x_{\mathrm{L}}$ overexpression protects MNs from apoptotic cell death caused by IKK $\alpha, I K K \beta$, or RelA interference. Mouse MNs were cotransduced with lentivirus containing the $\mathrm{hBCl}-\mathrm{x}_{\mathrm{L}}$ construct plus shIKK $\alpha$, shIKK $\beta$, shRelA, or the empty vector (Ctrl) or ANOVA test and Bonferroni's an antibody against $\alpha$-Tubulin, as a loading control. D, Total cell lysates of $5 \mathrm{~d}$ cotransduced cultures with $\mathrm{hBcl}$ - $\mathrm{x}_{\perp}$ plus shIKK $\alpha$ or shlKK $\beta$ or cultures transduced with shIKK $\alpha$, shIKK $\beta$, or Ctrl were probed with antibodies against IKK $\beta$ or IKK $\alpha$ by Western blot. The same membranes were reprobed with an antibody against $\alpha$-Tubulin as a loading control.

\section{Discussion}

In the present work, we demonstrate that the canonical NF- $\kappa \mathrm{B}$ pathway mediates cell survival in a primary culture of isolated mouse embryonic MNs. Reducing protein level of several members of the NF- $\kappa \mathrm{B}$ signaling pathway revealed that these proteins are essential to the ability of NTFs to promote MN survival. Inhibition of $\mathrm{I} \kappa \mathrm{B}$ kinases or the DNA-binding subunit RelA caused a very substantial reduction of MN survival and induced apoptotic cell death. However, reduction of RelB protein did not affect MN survival. The NF- $\kappa$ B pathway could be activated by two different routes: the canonical or classical and the noncanonical. The canonical pathway is characterized by the activation and the translocation of p50/RelA heterodimers to the nucleus, whereas the noncanonical pathway results from p52/RelB heterodimers activation and translocation (Perkins, 2007). It is known that p52/RelB have affinity for $\kappa$ B elements distinct from p50/RelA, and might therefore regulate a distinct subset of NF- $\kappa \mathrm{B}$ target genes. It is also believed that the subunit composition of the complexes may vary depending on factors such as the develop- 
A
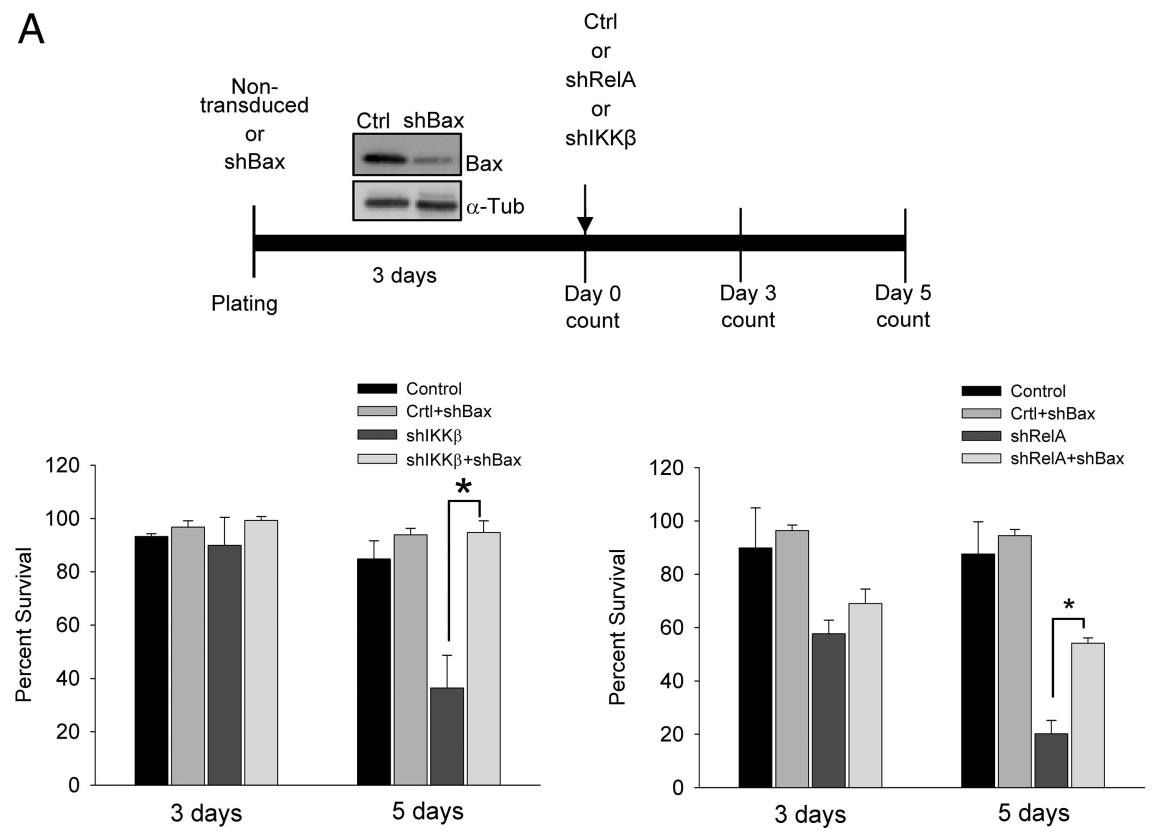

B Ctrl shIKK $\beta$

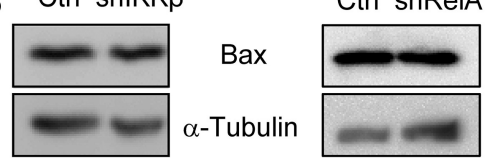

Figure 8. Bax protein knockdown rescues MNs from cell death caused by IKK $\beta$ or RelA interference. MNs were transduced with shBax or nontransduced; $3 \mathrm{~d}$ later, they were cotransduced or transduced with shIKK $\beta$, shRelA, or empty vector (Ctrl). Bax protein reduction was analyzed by Western blot using a specific antibody (see diagram). $\boldsymbol{A}$, Cell survival was measured as described in Materials and Methods. Graphs represent for each condition the mean percentage of survival of nine wells from three independent experiments \pm SEM (error bars). Asterisk indicates significant differences between data from the experiments using one-way ANOVA test and Bonferroni's post hoc multiple comparisons $\left({ }^{*} p<0.001\right)$. B. Protein extracts were collected from $5 \mathrm{~d}$ transduced cultures (shIKK $\beta$, shRelA, or Ctrl) and analyzed by Western blot using an anti-Bax antibody. Membranes were reprobed with an anti- $\alpha$-Tubulin antibody as a loading control.

mental state of the neurons and their location within the nervous system. In our culture system, we reduced RelA or RelB proteins to analyze the involvement of the canonical or the noncanonical NF- $\kappa \mathrm{B}$ pathway on MN survival. Our results clearly demonstrated that RelA reduction caused cell death, whereas RelB did not, indicating that only the canonical pathway is involved in NTF-induced MN survival, even though both pathways are activated in MNs after NTF treatment. The noncanonical signaling is characterized by IKK $\alpha$-dependent processing of p100 to p52 (Xiao et al., 2004), whereas both IKK $\alpha$ and IKK $\beta$ are associated with the activation of the canonical pathway (Perkins, 2007). The phosphorylation of these two kinases induces RelA release and translocation to the nucleus. In the present work, we show that NTF stimulation induces IKK phosphorylation, I $\kappa \mathrm{B} \alpha$ serine phosphorylation and degradation, and RelA translocation to the nucleus, indicating the activation of the canonical pathway. We also show p100 processing, demonstrating that NTFs also activate the noncanonical signaling. After IKK $\alpha$ or IKK $\beta$ knockdown, we observed reduction of cell survival and increase of apoptotic cell death. However, when RelB protein level was reduced, MN survival was not affected. This result reinforced the initial hypothesis that NF- $\kappa \mathrm{B}$ canonical pathway mediates MN survival and the cell death effect observed by IKK $\alpha$ knockdown is due to its role in the canonical signaling activation.

The NF- $\kappa \mathrm{B}$ canonical pathway has been related to cell survival during development. In fact, IKK $\beta$ (Li et al., 1999) or RelA (Beg et al., 1995) knock-out mice show embryonic lethality accompanied with a massive degeneration of the liver by apoptosis. The role of the canonical pathway during the development of the nervous system has been revealed by IKK $\alpha$ and IKK $\beta$ double-deficient mice. The double knockout demonstrated that both kinases are essential for NF- $\kappa \mathrm{B}$ activation and have an important role in protecting neurons against excessive apoptosis during development (Li et al., 2000). These authors also postulated that both IKKs might have a genetic redundancy during nervous system development.

NF- $\kappa \mathrm{B}$ has been studied more extensively in the immune system; however, it is known that in some neuronal populations NF- $\kappa \mathrm{B}$ activity induces cell survival. Early indications that NF- $\kappa \mathrm{B}$ activation promotes neuronal survival came from studies of embryonic hippocampal cells under stressing conditions (Cheng et al., 1994; Mattson et al., 1997), but there are other examples: in cerebellar granule cells, trophic factor withdrawal induces NF- $\kappa \mathrm{B}$ inactivation (Kovács et al., 2004) and NF- $\kappa \mathrm{B}$ activity contributes to promote survival in sympathetic NGF-dependent neurons (Maggirwar et al., 1998). Thus, strong evidence suggests that the NF- $\kappa \mathrm{B}$ pathway regulates cell survival of the central and peripheral nervous systems. Here we show for the first time that NF- $\kappa$ B is one of the central survival pathways of embryonic spinal cord MNs. It is also known that NF- $\kappa \mathrm{B}$ activity is related to other neuronal functions such as neurite outgrowth (Gallagher et al., 2007; Gutierrez et al., 2008), suggesting an important role of this pathway in neuronal development and probably in some neuronal diseases (Mattson and Meffert, 2006). For example, genes regulating NF- $\kappa \mathrm{B}$ pathway activity have been related to a novel form of lower motor neuron disease (Maystadt et al., 2007), indicating that indirect NF- $\kappa \mathrm{B}$ deregulation might be involved in neuronal diseases. The loss of NF- $\kappa \mathrm{B}$ activation could remove protection of neurons against apoptosis and thereby compromise survival. The recent description that IKK $\beta$ regulates pathogenesis of Huntington's disease by inducing cleavage of the mutated huntingtin (Khoshnan et al., 2009) suggests a direct involvement of NF- $\kappa$ B in neurodegenerative disorders. In our hands, when we knock down RelA, Smn protein level decreases. Smn protein is important during MN embryonic development (Schrank et al., 1997), and Smn reduction causes the lower MN neurodegenerative disorder spinal muscular atrophy (Sumner, 2006). The disease is characterized by the specific degeneration of MNs when Smn is reduced. The molecular mechanisms involved in this process are still unknown, and several hypotheses have been proposed. Here we show for the first time that the NF- $\kappa$ B pathway could regulate Smn protein level. In shRelA cultures, we also observed a decrease of CREB protein. It is also known that CREB protein increases SMN promoter activity (Majumder et al., 2004), suggesting the role of CREB in the molecular regulation of Smn level. 
The relevance of the NF- $\kappa \mathrm{B}$ pathway to cell survival is related to the induction of target genes whose products inhibit some aspects of the apoptotic machinery. In some cell lines and primary cultures, NGF or TNF induced an increase of $\mathrm{Bcl}-\mathrm{x}_{\mathrm{L}}$ protein level through the activation of the NF- $\kappa \mathrm{B}$ pathway (Bui et al., 2001). In our system, the NTF cocktail also increased the levels of Bcl$\mathrm{x}_{\mathrm{L}} \cdot \mathrm{Bcl}-\mathrm{x}_{\mathrm{L}}$ protein increases when $\mathrm{MNs}$ are maintained in the presence of NTFs, but not when NTFs are absent in the culture medium. However, we did not observe differences in $\mathrm{Bcl}-\mathrm{x}_{\mathrm{L}}$ levels when NF- $\kappa \mathrm{B}$ was blocked by shIKK $\beta$, shRelA, or $\operatorname{shIKK} \alpha$, indicating that the NF- $\kappa \mathrm{B}$ pathway is not directly regulating $\mathrm{Bcl}-\mathrm{x}_{\mathrm{L}}$ protein level. However, when $\mathrm{Bcl}-\mathrm{x}_{\mathrm{L}}$ protein was increased by overexpression, the apoptosis caused by NF- $\kappa \mathrm{B}$ pathway blockade, was completely abolished. In the same line of evidence, we show that Bax protein reduction is able to rescue cells from apoptosis when $\mathrm{NF}-\kappa \mathrm{B}$ is reduced. Thus, from these results we can conclude that the NF- $\kappa \mathrm{B}$ pathway could be regulating at least a $\mathrm{Bcl}-\mathrm{x}_{\mathrm{L}}$ upstream mechanism associated with NF- $\kappa \mathrm{B}$ activity. Our work demonstrates that the $\mathrm{NF}-\kappa \mathrm{B}$ family of proteins is necessary for MN survival; knockdown of these proteins probably deregulates gene expression of proteins that exert their function upstream of the mitochondria. It has been recently demonstrated that the $\mathrm{BH} 3$-only protein, Bim, displaces $\mathrm{Bcl}-\mathrm{x}_{\mathrm{L}}$ in the mitochondria and promotes Bax translocation during TNF $\alpha$-induced apoptosis in PC12 cells (Zhang et al., 2008). In our model, we observed in shRelA-treated cultures an increase of Bim protein level, suggesting that this protein could be regulating the apoptotic cell death process caused by the blockade of NF- $\kappa \mathrm{B}$ signaling.

In summary, our results demonstrate that NF- $\kappa \mathrm{B}$ can mediate NTF-induced cell survival in developing MNs and regulate the expression of proteins involved in MN neurodegenerative disorders. We describe in Figure $9 \mathrm{C}$ a schematic model showing the proposed mechanism of the effect of NTF treatment on the NF- $\kappa \mathrm{B}$ pathway through the activation of PI 3-kinase and the later expression of Smn, CREB, and Bim proteins.

\section{References}

Airaksinen MS, Saarma M (2002) The GDNF family: signalling, biological functions and therapeutic value. Nat Rev Neurosci 3:383-394.

Arce V, Garces A, de Bovis B, Filippi P, Henderson C, Pettmann B, deLapeyrière O (1999) Cardiotrophin-1 requires LIFRbeta to promote survival of mouse motoneurons purified by a novel technique. J Neurosci Res $55: 119-126$.

Beg AA, Sha WC, Bronson RT, Ghosh S, Baltimore D (1995) Embryonic lethality and liver degeneration in mice lacking the RelA component of NF-kappa B. Nature 376:167-170.

Bhakar AL, Tannis LL, Zeindler C, Russo MP, Jobin C, Park DS, MacPherson S, Barker PA (2002) Constitutive nuclear factor- $\kappa \mathrm{B}$ activity is required for central neuron survival. J Neurosci 22:8466-8475.

Bui NT, Livolsi A, Peyron JF, Prehn JH (2001) Activation of nuclear factor kappaB and $\mathrm{Bcl}-\mathrm{x}$ survival gene expression by nerve growth factor requires tyrosine phosphorylation of IkappaBalpha. J Cell Biol 152:753-764

Chao MV (2003) Neurotrophins and their receptors: a convergence point for many signalling pathways. Nat Rev Neurosci 4:299-309.

Cheng B, Christakos S, Mattson MP (1994) Tumor necrosis factors protect neurons against metabolic-excitotoxic insults and promote maintenance of calcium homeostasis. Neuron 12:139-153.

Delhase M, Hayakawa M, Chen Y, Karin M (1999) Positive and negative regulation of IkappaB kinase activity through IKKbeta subunit phosphorylation. Science 284:309-313.

Dolcet X, Soler RM, Gould TW, Egea J, Oppenheim RW, Comella JX (2001) Cytokines promote motoneuron survival through the Janus kinasedependent activation of the phosphatidylinositol 3-kinase pathway. Mol Cell Neurosci 18:619-631.

Dolcet X, Llobet D, Encinas M, Pallares J, Cabero A, Schoenenberger JA, Comella JX, Matias-Guiu X (2006) Proteasome inhibitors induce death but activate NF-kappaB on endometrial carcinoma cell lines and primary culture explants. J Biol Chem 281:22118-22130.

Encinas M, Rozen EJ, Dolcet X, Jain S, Comella JX, Milbrandt J, Johnson EM Jr (2008) Analysis of Ret knockin mice reveals a critical role for IKKs, but not PI 3-K, in neurotrophic factor-induced survival of sympathetic neurons. Cell Death Differ 15:1510-1521.

Gallagher D, Gutierrez H, Gavalda N, O’Keeffe G, Hay R, Davies AM (2007) Nuclear factor $-\kappa \mathrm{B}$ activation via tyrosine phosphorylation of inhibitor $\kappa \mathrm{B}-\alpha$ is crucial for ciliary neurotrophic factor-promoted neurite growth from developing neurons. J Neurosci 27:9664-9669. 
González-García M, García I, Ding L, O’Shea S, Boise LH, Thompson CB, Núñez G (1995) bcl-x is expressed in embryonic and postnatal neural tissues and functions to prevent neuronal cell death. Proc Natl Acad Sci U S A 92:4304-4308.

Gou-Fabregas M, Garcera A, Mincheva S, Perez-Garcia MJ, Comella JX, Soler RM (2009) Specific vulnerability of mouse spinal cord motoneurons to membrane depolarization. J Neurochem 110:1842-1854.

Gutierrez H, O'Keeffe GW, Gavaldà N, Gallagher D, Davies AM (2008) Nuclear factor $\kappa \mathrm{B}$ signaling either stimulates or inhibits neurite growth depending on the phosphorylation status of p65/RelA. J Neurosci 28:8246-8256.

Hayden MS, Ghosh S (2004) Signaling to NF-kappaB. Genes Dev 18: 2195-2224

Holtmann B, Wiese S, Samsam M, Grohmann K, Pennica D, Martini R, Sendtner M (2005) Triple knock-out of CNTF, LIF, and CT-1 defines cooperative and distinct roles of these neurotrophic factors for motoneuron maintenance and function. J Neurosci 25:1778-1787.

Kaltschmidt B, Widera D, Kaltschmidt C (2005) Signaling via NF-kappaB in the nervous system. Biochim Biophys Acta 1745:287-299.

Khoshnan A, Ko J, Tescu S, Brundin P, Patterson PH (2009) IKKalpha and IKKbeta regulation of DNA damage-induced cleavage of huntingtin. PLoS One 4:e5768.

Koulich E, Nguyen T, Johnson K, Giardina C, D’Mello S (2001) NF-kappaB is involved in the survival of cerebellar granule neurons: association of IkappaBbeta [correction of Ikappabeta] phosphorylation with cell survival. J Neurochem 76:1188-1198.

Kovács AD, Chakraborty-Sett S, Ramirez SH, Sniderhan LF, Williamson AL, Maggirwar SB (2004) Mechanism of NF-kappaB inactivation induced by survival signal withdrawal in cerebellar granule neurons. Eur J Neurosci 20:345-352.

Li Q, Estepa G, Memet S, Israel A, Verma IM (2000) Complete lack of NFkappaB activity in IKK1 and IKK2 double-deficient mice: additional defect in neurulation. Genes Dev 14:1729-1733.

Li ZW, Chu W, Hu Y, Delhase M, Deerinck T, Ellisman M, Johnson R, Karin M (1999) The IKKbeta subunit of IkappaB kinase (IKK) is essential for nuclear factor kappaB activation and prevention of apoptosis. J Exp Med 189:1839-1845

Lin YZ, Yao SY, Veach RA, Torgerson TR, Hawiger J (1995) Inhibition of nuclear translocation of transcription factor NF-kappa B by a synthetic peptide containing a cell membrane-permeable motif and nuclear localization sequence. J Biol Chem 270:14255-14258.

Maggirwar SB, Sarmiere PD, Dewhurst S, Freeman RS (1998) Nerve growth factor-dependent activation of NF- $\kappa \mathrm{B}$ contributes to survival of sympathetic neurons. J Neurosci 18:10356-10365.

Majumder S, Varadharaj S, Ghoshal K, Monani U, Burghes AH, Jacob ST (2004) Identification of a novel cyclic AMP-response element (CRE-II) and the role of CREB- 1 in the CAMP-induced expression of the survival motor neuron (SMN) gene. J Biol Chem 279:14803-14811.

Mattson MP, Meffert MK (2006) Roles for NF-kappaB in nerve cell survival, plasticity, and disease. Cell Death Differ 13:852-860.

Mattson MP, Goodman Y, Luo H, Fu W, Furukawa K (1997) Activation of
NF-kappaB protects hippocampal neurons against oxidative stressinduced apoptosis: evidence for induction of manganese superoxide dismutase and suppression of peroxynitrite production and protein tyrosine nitration. J Neurosci Res 49:681-697.

Mattson MP, Culmsee C, Yu Z, Camandola S (2000) Roles of nuclear factor kappaB in neuronal survival and plasticity. J Neurochem 74:443-456.

Maystadt I, Rezsöhazy R, Barkats M, Duque S, Vannuffel P, Remacle S, Lambert B, Najimi M, Sokal E, Munnich A, Viollet L, Verellen-Dumoulin C (2007) The nuclear factor kappaB-activator gene PLEKHG5 is mutated in a form of autosomal recessive lower motor neuron disease with childhood onset. Am J Hum Genet 81:67-76.

Oppenheim RW (1996) Neurotrophic survival molecules for motoneurons: an embarrassment of riches. Neuron 17:195-197.

Pérez-García MJ, Ceña V, de Pablo Y, Llovera M, Comella JX, Soler RM (2004) Glial cell line-derived neurotrophic factor increases intracellular calcium concentration. Role of calcium/calmodulin in the activation of the phosphatidylinositol 3-kinase pathway. J Biol Chem 279:6132-6142.

Perkins ND (2007) Integrating cell-signalling pathways with NF-kappaB and IKK function. Nat Rev Mol Cell Biol 8:49-62.

Piccioli P, Porcile C, Stanzione S, Bisaglia M, Bajetto A, Bonavia R, Florio T, Schettini G (2001) Inhibition of nuclear factor-kappaB activation induces apoptosis in cerebellar granule cells. J Neurosci Res 66:1064-1073.

Schrank B, Götz R, Gunnersen JM, Ure JM, Toyka KV, Smith AG, Sendtner M (1997) Inactivation of the survival motor neuron gene, a candidate gene for human spinal muscular atrophy, leads to massive cell death in early mouse embryos. Proc Natl Acad Sci U S A 94:9920-9925.

Soler RM, Egea J, Mintenig GM, Sanz-Rodriguez C, Iglesias M, Comella JX (1998) Calmodulin is involved in membrane depolarization-mediated survival of motoneurons by phosphatidylinositol-3 kinase- and MAPKindependent pathways. J Neurosci 18:1230-1239.

Soler RM, Dolcet X, Encinas M, Egea J, Bayascas JR, Comella JX (1999) Receptors of the glial cell line-derived neurotrophic factor family of neurotrophic factors signal cell survival through the phosphatidylinositol 3-kinase pathway in spinal cord motoneurons. J Neurosci 19:9160-9169.

Sumner CJ (2006) Therapeutics development for spinal muscular atrophy. NeuroRx 3:235-245.

Tian B, Nowak DE, Jamaluddin M, Wang S, Brasier AR (2005) Identification of direct genomic targets downstream of the nuclear factor-kappaB transcription factor mediating tumor necrosis factor signaling. J Biol Chem 280:17435-17448.

Wei MC, Zong WX, Cheng EH, Lindsten T, Panoutsakopoulou V, Ross AJ, Roth KA, MacGregor GR, Thompson CB, Korsmeyer SJ (2001) Proapoptotic BAX and BAK: a requisite gateway to mitochondrial dysfunction and death. Science 292:727-730.

Xiao G, Fong A, Sun SC (2004) Induction of p100 processing by NFkappaB-inducing kinase involves docking IkappaB kinase alpha (IKKalpha) to p100 and IKKalpha-mediated phosphorylation. J Biol Chem 279:30099-30105.

Zhang L, Xing D, Chen M (2008) Bim(L) displacing Bcl-x(L) promotes Bax translocation during TNFalpha-induced apoptosis. Apoptosis 13:950958. 